\title{
A Brasília de Alberto Moravia
}

Adriana Marcolini

\section{Acerca de Alberto Moravia}

O escritor e jornalista italiano Alberto Moravia (1907-1990) escreveu seu primeiro romance - Gli indifferenti [Os Indiferentes] - em 1929. A publicação, que lançou seu nome na cena literária de seu país, obteve um enorme sucesso e trouxe à tona a dissolução moral, o estranhamento recíproco, a frieza e a indiferença no seio de uma família da burguesia italiana durante os primeiros anos do fascismo. Moravia publicou outros romances, como La Romana [A Romana], Il Conformista [O Conformista] e 1934 [1934], entre vários. Também escreveu livros de contos, ensaios e peças teatrais. Várias de suas obras foram adaptadas para o cinema. Foi agraciado em 1952 com o prêmio literário Strega, um dos mais prestigiosos da Itália.

Alberto Moravia se chamava na realidade Alberto Pincherle e vinha de uma família de ascendência judaica. Adotou o pseudônimo aos 23 anos, para driblar o regime fascista. Sua visita ao Brasil, em 1960, se insere em uma longa série de viagens que empreendeu como enviado especial da imprensa italiana. Em agosto de 1930, um convite para trabalhar no jornal La Stampa, na época sob a direção do escritor Curzio Malaparte, introduziu-o no mundo do jornalismo. Com uma nova identidade e cansado de respirar a atmosfera pesada do fascismo, Moravia foi enviado naquele mesmo ano para a Inglaterra, onde escreveu seus primeiros relatos de viagem, publicados entre 1930 e 1932. Ele mostrou ser um observador arguto já nos artigos iniciais, combinando uma inteligência aguda com uma rara capacidade de síntese. Seu poder de condensação marca sobremaneira seus textos de viagem, conferindo-lhes um caráter jornalístico próprio dos artigos publicados na grande imprensa. 
A partir da viagem a Inglaterra, em 1930, teve início uma longa trajetória que levou Moravia a visitar inúmeros países e a percorrer exaustivamente a Europa, a América do Norte, o Oriente Médio, a Ásia, a África e a América Latina. A distância geográfica, as dificuldades de locomoção e os idiomas estranhos não o desanimavam. Pelo contrário: funcionavam como combustível. O escritor diziase fascinado pelo Terceiro Mundo e nutria uma particular atração pela África, continente por ele definido como "a coisa mais bela que existe no mundo". Dedicou-se a literatura de viagem por nada menos que seis décadas.

Provavelmente, o principal motivo que o trouxe ao Brasil tenha sido a inauguração de Brasília, em abril de 1960. Concluída apenas 15 anos após o fim da Segunda Guerra Mundial, a nova capital carregava um forte simbolismo com sua aura de modernidade e futuro, atraindo a atenção dos europeus sedentos de esperança. $\mathrm{O}$ artigo sobre Brasília faz parte de uma série de seis relatos sobre o Brasil publicados pelo jornal milanês Corriere della Sera, em 1960. Todos foram traduzidos por mim e publicados pelo extinto caderno Mais!, da Folha de S.Paulo, em 25 de janeiro de 2009. A tradução que ora publico contém o texto completo; aquela publicada pelo jornal recebeu alguns cortes (devidamente assinalados na edição impressa do Mais:) por falta de espaço. Os leitores puderam ter acesso à tradução completa na edição online do jornal.

Os relatos sobre o Brasil estão incluídos na coletânea VLAGGI Articoli 1930-1990, onde se encontram praticamente todos os artigos de viagem de Alberto Moravia. Esse livro foi publicado em 1994 pela editora Bompiani, de Milão - que detém os direitos autorais do escritor. A leitura dos relatos revela que o autor não cultivava a retórica e o enaltecimento gratuito das pessoas e lugares que visitava. Seu texto é límpido, direto, questionador.

A publicação desta tradução conta com a autorização expressa da editora. 


\section{Notas sobre a tradução}

Foi um prazer e ao mesmo tempo um desafio fazer esta tradução. A maior dificuldade que tive foi respeitar, em português, o ritmo do escritor - latente no trecho a seguir ${ }^{1}$ :

Eis a chamada cidade livre, um turbilhão de pequenos retângulos, ou melhor, de barracões, alinhados ao longo de uma rua enorme: como no Far West, na época da febre do ouro, aqui se aglomeram os comerciantes que chegam aos montes de todos os lugares (é ouro, porém, o que o Estado brasileiro gasta em Brasília); eis, em pé aqui e ali, tal qual peças de dominó desordenadas, os ainda raros edifícios; eis a meia-lua azul do lago artificial entre o tom avermelhado de sangue das escavações e o amarelado da vegetação; eis as complicadas aortas pretas deste coração de cimento, melhor dizendo, o sistema viário planejado por Lúcio Costa, o mais moderno do mundo, pelo que parece; eis, em volta de Brasília, o crescimento danoso e ingrato da mata que, como sabemos, prolonga-se por milhares de quilômetros, em meio aos quais a cidade caiu como um meteoro em chamas, sacrificando a terra árida com sangue.

O parágrafo é longo e remete para a cadência ritmada do artigo. O texto "respira" com a expressão ecco, utilizada cinco vezes pelo autor. Acompanhar esta respiração foi instigante. Também procurei traduzir as cores em suas tonalidades; assim, traduzi "cimento amarelado" ["no final, abaixo das torres, surge um longo edifício horizontal sobre o qual pousam duas frigideiras enormes de cimento amarelado, uma virada para baixo e outra virada para cima"] e não "cimento amarelo", por acreditar que a tonalidade de uma cor expressa muito mais caráter literário que a cor em si.

Para concluir, penso que quando traduzimos uma obra literária devemos nos lembrar que a literatura é a arte do que está oculto, do que é dito em meias palavras. Procurei respeitar isto.

1 [ecco la cosidetta città libera, un brulichio di rettangolini, cioè baracche, allineati lungo uno stradone immenso: qui si affollano, come nel Far West, al tempo della febbre dell'oro, i trafficanti piovuti d'ogni parte (ma l'oro è quello che lo Stato brasiliano spende a Brasilia); ecco, ritti qua e là, come pezzi di domino in disordine, gli ancor rari edifici; ecco, la mezzaluna azzurra del lago artificiale tra il rosso di sangue degli sterrati e il giallo itterico della macchia; ecco le complicate aorte nere di questo cuore di cemento ossia il sistema stradale ideato da Lucio Costa, il più moderno del mondo, a quanto sembra; ecco, tutt'intorno Brasilia, il pullulare maligno e ingrato della macchia, estesa, come sappiamo, migliaia di chilometri e in mezzo alla quale la città è piombata come una meteorite ardente, sacrificando a sangue la terra arida] 


\section{Brasília}

Olhando do avião, o lugar onde está Brasília, situada, como se fosse por acaso, entre as infinitas ondulações horizontais do planalto (embora pareça que, após cálculos muito precisos, este lugar tenha sido escolhido por ser o mais central do Brasil) leva a pensar em um monte de bifes ensanguentados expostos no balcão de um açougueiro. Formas quadradas mais ou menos vermelhas de acordo com a época mais ou menos recente das escavações de terra revelam as áreas destinadas à construção dos edifícios, que foram arrancadas da vegetação tropical. O avião demora a aterrissar porque a pista não está livre - o que é freqüente neste país com poucas estradas e poucas ferrovias, mas de aeroportos congestionados - e plana várias vezes sobre Brasília. Eis a chamada cidade livre, um turbilhão de pequenos retângulos, ou melhor, de barracões, alinhados ao longo de uma rua enorme: como no Far West, na época da febre do ouro, aqui se aglomeram os comerciantes que chegam, aos montes, de todos os lugares (é ouro, porém, o que o Estado brasileiro gasta em Brasília); eis, em pé aqui e ali, tal qual peças de dominó desordenadas, os ainda raros edifícios; eis a meia-lua azul do lago artificial entre o tom avermelhado de sangue das escavações e o amarelado da vegetação; eis as complicadas aortas pretas deste coração de cimento, melhor dizendo, o sistema viário planejado por Lúcio Costa, o mais moderno do mundo, pelo que parece; eis, em volta de Brasília, o crescimento danoso e ingrato da mata, que, como sabemos, prolonga-se por milhares de quilômetros, em meio aos quais a cidade caiu como um meteoro em chamas, sacrificando a terra árida com sangue. Do alto, a vontade que deu origem à Brasília vem à tona com clareza: criar uma capital abstrata para um país enorme, cuja unidade também é um milagre de abstração linguística e étnica; penetrar com a força do Estado no interior selvagem do Brasil depois que as incursões individuais não deram grandes resultados; arrancar a classe dirigente brasileira das cidades costeiras preguiçosas e barrocas e obrigá-la a retomar com os meios modernos a marcha dos antigos colonizadores em direção ao interior. Brasília, capital burocrática como Ancara, como Washington, como Camberra, saberá ela ser mais vivaz que essas cidades construídas pela força da vontade? Acreditamos que sim, se não for por outro motivo, porque, como dissemos, a ambição de Brasília é dupla: não apenas se tornar a capital do país, mas também assumir a função de trampolim para a colonização e civilização dos vastíssimos territórios do noroeste e nordeste.

O carro corre agora por uma grande rua asfaltada, de largura imensurável, entre duas faixas de uma mata amarelada e contorcida, que parece sofrer por existir, em direção ao céu azul vazio. Eis então surgindo lentamente no horizonte 
duas torres, ou melhor, dois retângulos estreitos e altíssimos, ligados por uma ponte, semelhantes às lentes de um binóculo gigantesco. É o edifício do governo, construído, como toda Brasília, segundo os projetos de Oscar Niemeyer, o arquiteto genial que teve a sorte de receber a encomenda não de um edifício ou de um conjunto de edifícios, mas de uma capital inteira. As duas torres sobem, sobem repletas de centenas de janelas; no final, abaixo das torres, surge um longo edifício horizontal sobre o qual pousam duas frigideiras enormes de cimento amarelado, uma virada para baixo e outra virada para cima. Por um momento os olhos não acreditam no que veem uma vez que, enquanto até um arranha-céu altíssimo é aceitável justamente por ser geométrico; a naturalidade de uma sopeira - que parece ser feita para o apetite de um gigante - tem alguma coisa de alucinante. E de fato, por um instante sentimos que somos como os minúsculos habitantes de Lilliput e quase involuntariamente procuramos no céu vazio a forma ameaçadora de um novo Gulliver.

Não há gigantes; mas a impressão de gigantismo arquitetônico e, portanto, de esmagamento e aniquilação da figura humana permanece e se afirma durante toda a visita. Brasília foi construída por vontade de Kubitschek, que é um Presidente democrático, para um Brasil democrático; no entanto, a observação daqueles edifícios que se elevam como torres no meio de enormes espaços vazios faz pensar em lugares e monumentos de antigas autocracias, por exemplo, em Persépolis, que tinha suas colunas gigantescas em frente a uma planície não muito diferente daquela de Brasília. A atmosfera ditatorial é, por outro lado, confirmada pela solidão metafísica dos lagos de asfalto, em que surgem os edifícios. Essas solidões urbanas, antecipadas nas perspectivas surrealistas de De Chirico e Dalí, expressam muito bem o sentido de mistério e desorientação que o homem moderno sente diante dos poderes que o governam. Mas talvez sejam impressões precipitadas porque, em Brasília, as coisas foram feitas ao contrário: outrora surgiam inicialmente as casas de moradia, depois vinham os edifícios monumentais; em Brasília, se começou com esses últimos; as casas de moradia serão construídas no futuro.

Antes de qualquer outra coisa o Brasil é um país de arquitetos e Brasília é, antes de tudo, um experimento arquitetônico. Mas, para entender Brasília, é preciso, em nossa opinião, referir-se ao Brasil colonial da Bahia e das outras cidades barrocas do litoral. É bom que se fique sabendo: a relação não é formal e estilística, mas, sim, psicológica. Ao barroco delirante das igrejas coloniais corresponde de fato, no sentido psicológico, o gigantismo não menos exaltado de Brasília. Fica então claro que estamos diante de uma explosão barroca mascarada de funcionalismo. Tomemos como exemplo o já descrito edifício do governo: a altura 
imensurável das duas torres encostadas de tal forma a não permitir que as janelas de dentro tenham sol ou vista; a naturalidade extravagante das frigideiras gigantescas pousadas no terraço do edifício horizontal; a imensa ponte inclinada que leva do espaço para esse terraço, isto é, a absolutamente nada e que não tem outra função que não seja a decorativa, tudo induz a uma concepção grandiloquente, embora expressa com uma linguagem moderna. $\mathrm{Na}$ verdade, houve aqui um toque de orgulho exatamente como em certas cidades da antiguidade, fundadas depois de uma conquista cruel. O orgulho de um país novo que, pela segunda vez na sua história, prepara-se para partir à conquista de si mesmo.

De resto, a confirmação da ambição especialmente monumental de Brasília está no interior desses prédios grandiosos que com muita frequência desiludem pelo conjunto e convencionalismo das soluções; é quase como se o entusiasmo da celebração tenha se esgotado nas principais estruturas e não tenha havido a preocupação de cuidar dos detalhes. À originalidade sedutora das fachadas não corresponde uma originalidade semelhante atrás das fachadas: salas sinuosas e imensas a perder de vista, com tetos excessivamente baixos, pontilhadas de robustas colunas cilíndricas, que trazem saudades das tradicionais divisões de paredes e portas; escadas largas e sem balaústre, que levam do primeiro ao segundo andar sem nenhuma graça, tal como nas grandes lojas e nas docas; principalmente cimento armado em todos os lugares, mesmo no revestimento e na decoração, onde se esperaria o uso de materiais mais bonitos e de mais prestígio.

Em resumo, o edifício tão corajoso por fora revela-se preguiçoso e apressado por dentro. Não é possível negar que o julgamento aqui também é precipitado porque o edifício ainda não recebeu seus últimos retoques. Encontra-se pronta, por exemplo, a sala do Parlamento, que fica dentro da grande frigideira virada para cima. Pois bem, nada nessa sala corresponde à audácia da parte exterior. É uma linda sala, cômoda, alta, austera, mas nada demais.

Se os edifícios do governo visam a expressar o sentido de concentração e potência do Estado, o palácio da Alvorada, residência do Presidente da Repúbli$\mathrm{ca}$, ou seja, o equivalente ao nosso Quirinale, parece sugerir a ideia de uma serenidade contemplativa e de um recolhimento filosófico e estético, quase como se a República do Brasil fosse a república de Platão dirigida por sábios, com base somente em critérios de sabedoria. Portanto, nada de linhas verticais e nada de gigantismo. Um grande átrio sustentado por pórticos percorre toda a longa fachada horizontal e se reflete na água límpida de uma grande bacia de cores claras e brilhantes de maiólica. No lugar das colunas, os pórticos são erguidos em pedra com a forma de velas, modeladas de forma a parecerem inchar com a brisa marinha, como se fossem vistas de lado, largas embaixo e em cima, e estreitas no 
meio, talvez uma reminiscência da embarcação nacional, a jangada do Recife e da Bahia, ou talvez das velas dos barcos da Ilíada. O céu azul do planalto que vagueia entre uma e outra dessas velas brancas; o sol dos trópicos que aqui nesta altitude de Brasília resplandece, mas não queima; o silêncio profundo que emana da selva próxima; o voo prudente de algumas aves predadoras; tudo aqui leva a pensar nos lugares e monumentos da antiguidade mediterrânea dos quais o arquiteto parece ter se lembrado ao projetar esse edifício. É certo que com o Alvorada Oscar Niemeyer criou algo muito próximo de uma obra-prima. Pelo menos é isso o que dá a entender a identidade entre a intenção do arquiteto e o efeito que o edifício produz no visitante. Não existe nenhuma retórica no Alvorada, mas sim uma fusão feliz de elementos ambientais e ideais, de maneira que, se não houvesse os dois sentinelas de metralhadora debaixo do braço, medindo com passos lentos as peças de mármore branco do espaço vazio, não seria difícil, por analogia, transportar-se com a imaginação para lugares muito longe do Brasil, para a Pérsia ou a Grécia.

Mas o interior do Alvorada não se parece com a parte externa, como sempre. Passa-se do conjunto de pórticos luminosos e meditativos a grandes salas alegres e cômodas, que poderiam ser de um country-club americano. Na entrada as paredes são cobertas de um cintilante revestimento áureo; cortinas modernistas recobrem as janelas enormes; poltronas e sofás estão dispostos à maneira convencional de sempre. Enfim, à simplicidade da república platônica à qual os pórticos pareciam fazer alusão, se sobrepõem o luxo e a pompa dos reinos helenísticos. Nota-se esse mesmo contraste entre a parte externa e interna da pequena e bastante original capela que fica ao lado do palácio. Do lado de fora, ela lembra uma simples concha virada para dentro de si, como se quisesse encerrar melhor, no mais íntimo dos recolhimentos, os altares e os ritos: mas, por dentro, que pena: em vez de deixá-la branca, como justamente são as conchas, preferiu-se revesti-la de estuque ou, talvez, de madeira dourada, listrada de alto a baixo, como certos estojos para cigarros.

O pôr do sol nos surpreende ao final da visita apressada de Brasília, de forma repentina e traidora. Um momento antes o sol enchia com sua luz vital as grandes ruas asfaltadas e desertas, as escavações de coloração sanguínea, a vegetação poeirenta; um momento depois, eis que a sombra da noite retira aquela vitalidade do ar que escurece e de repente enquanto nos dirigimos para o aeroporto, ultrapassados e seguidos por numerosos caminhões abarrotados de operários que voltam dos canteiros de obras, a atmosfera à nossa volta torna-se estrangeira e hostil. A vegetação tropical que havíamos esquecido visitando os edifícios racionais da cidade aparece novamente, amarelada e decrépita, atrás da tatuagem 
roxa de algumas placas de ruas em néon. As miríades de lâmpadas brancas que se distanciam na noite parecem penetrar em uma escuridão sem fim. E de repente sente-se a falta, em meio a tanta monumentalidade dos edifícios estatais e tanta leveza nos asfaltos, das casas humildes e das ruas humildes que em outros lugares são o testemunho da presença de uma humanidade talvez pouco ambiciosa, mas fiel e enraizada. Assim, depois da visita, Brasília reaparece como a havíamos imaginado do avião, ao chegar: um ato de coragem pioneiro; o símbolo de uma vontade de conquista; a demonstração de uma possibilidade de longo prazo. À luz desta reflexão o gigantismo de Brasília parece ter uma explicação; (assim) como o barroco das igrejas construídas nas cidades do litoral pelos primeiros colonizadores.

Corriere della Sera, 28 de agosto de 1960.

\section{Brasilia}

Dall'aeroplano il luogo di Brasilia, situato come a caso tra le infinite ondulazioni orizzontali dell'altipiano (ma a quanto pare questo luogo è stato scelto dopo calcoli molto precisi come il più centrale del Brasile) fa pensare all'esposizione, sul banco di un macellaio, di una quantità di bistecche sanguinolente. Riquadri più o meno rossi secondo l'epoca più o meno recente degli sterramenti, rivelano le aree fabbricabili che sono state strappate alla macchia tropicale. L'aeroplano indugia ad atterrare perchè la pista non è libera, caso non infrequente in questo paese con poche strade e poche ferrovie ma dagli aeroporti congestionati, e fa più e più volte, planando, il giro di Brasilia. Ecco la cosidetta città libera, un brulichio di rettangolini, cioè baracche, allineati lungo uno stradone immenso: qui si affollano, come nel Far West, al tempo della febbre dell'oro, i trafficanti piovuti d'ogni parte (ma l'oro è quello che lo Stato brasiliano spende a Brasilia); ecco, ritti qua e là, come pezzi di domino in disordine, gli ancor rari edifici; ecco, la mezzaluna azzurra del lago artificiale tra il rosso di sangue degli sterrati e il giallo itterico della macchia; ecco le complicate aorte nere di questo cuore di cemento ossia il sistema stradale ideato da Lucio Costa, il più moderno del mondo, a quanto sembra; ecco, tutt'intorno Brasilia, il pullulare maligno e ingrato della macchia, estesa, come sappiamo, migliaia di chilometri e in mezzo alla quale la città è piombata come una meteorite ardente, sacrificando a sangue la terra arida. Dall'alto, la volontà che è all'origine di Brasilia si rivela chiaramente: creare una capitale astratta per un paese immenso la cui unità è anch'essa un miracolo di astrazione linguistica ed etnica; penetrare con la forza dello Stato 
nell'interno selvaggio del Brasile, dopo che le penetrazioni individuali sono in parte fallite; strappare la clase dirigente brasiliana dalle molli e barocche città della costa e costringerla a riprendere con mezzi moderni la marcia verso l'interno degli antichi colonizzatori. Brasilia, capitale burocratica, come Ankara, come Washington, come Canberra, saprà essere più viva di queste città volontaristiche? Pensiamo di sì, se non altro perchè, come abbiamo detto, l'ambizione di Brasilia è doppia: non soltanto diventare la capitale del paese, ma anche assumere la funzione di trampolino per la colonizzazione e l'incivilimento dei vastissimi territori del nord-ovest e del nord-est.

Adesso la macchina corre per uno stradone asfaltato di larghezza smisurata, tra due strisce di una boscaglia gialla e contorta che pare soffrire di esistere, incontro al vuoto cielo azzurro. Quindi all'orizzonte, ecco sorgere lentamente due torri o meglio due rettangoli stretti ed altissimi, congiunti da un ponte, simili ai cannochiali abbinati di un gigantesco binocolo. È l'edificio del Governo, costruito, come tutta Brasilia, secondo i progetti di Oscar Niemayer, l'architetto geniale che ha avuto la fortuna di vedersi commissionato non un palazzo o un gruppo di palazzi bensì una intera capitale. Le due torri salgono, salgono, gremite di centinaia di finestre, e alla fine sotto le torri emerge un lungo edifício orizzontale sul quale stanno posate due colossali scodelle di cemento giallognolo, una capovolta e l'altra ritta. Per un momento gli occhi non credono a quello che vedono giacché, mentre un grattacielo anche altissimo è accettabile appunto perché geometrico, il naturalismo di una zuppiera che sembra fatta per gli appetiti di un gigante ha qualche cosa di allucinante. E infatti, per un istante, ci sentiamo lillipuziani e quasi involontariamente cerchiamo nel cielo vuoto la forma minacciosa di un nuovo Gulliver.

Non ci sono giganti; ma l'impressione di gigantismo architettonico e dunque di schiacciamento e annichilimento della figura umana permane e si afferma via via che continua la visita. Brasilia è stata voluta da Kubitscek che è un Presidente democratico, per un Brasile democratico; tuttavia osservando quegli edifici torreggianti nel mezzo di immensi spazi vuoti, vien fatto di pensare a luoghi e monumenti di antiche autocrazie, per esempio a Persepoli che levava i suoi colonnati giganteschi di fronte ad una pianura non molto diversa da quella di Brasilia. L'atmosfera dittatoriale è, del resto, confermata dalla solitudine metafisica dei laghi d'asfalto nel mezzo dei quali sorgono gli edifici. Queste solitudini urbane anticipate nelle prospettive surrealistiche di De Chirico e di Dalì esprimono molto bene il senso del mistero e di sgomento che l'uomo moderno prova di fronte ai poteri che lo governano. Ma forse sono impressioni premature dovute al fatto che a Brasilia si è proceduto alla rovescia: un tempo le prime a sorgere erano le 
case di abitazione, poi venivano gli edifici monumentali; a Brasilia si è cominciato con questi ultimi; alle case di abitazione si provvederà in futuro.

Il Brasile è un Paese prima di tutto di architetti e Brasilia è prima di tutto un esperimento di architettura. Ma per capire Brasilia, bisogna, secondo noi, rifarsi al Brasile coloniale di Bahia e delle altre città barrocche della costa. Il nesso non è, beninteso, formale e stilistico, bensì psicologico. Al barocco delirante delle chiese coloniali corrisponde infatti, in senso psicologico, il gigantismo non meno esalta to di Brasilia. È chiaro cosi che ci troviamo di fronte ad un'esplosione barocca mascherata da funzionalismo. Prendiamo per esempio il già descritto pallazzo del Governo: l'altezza smisurata delle due torri accostate strettamente in modo che le finestre dell'interno non avranno sole né vista; il naturalismo stravagante delle due gigantesche scodelle posate sulla terrazza dell'edificio orizzontale; l'immenso cavalcavia a piano inclinato che dallo spiazzo porta a questa terrazza cioè ad un bel nulla e non ha altra funzione se non decorativa, tutto lascia indovinare una concezione grandiloquente benché espressa com linguaggio moderno. In realtà qui è statta detta uma parola di orgoglio come appunto in certe città dell'antichità fondate dopo una conquista cruenta. L'orgoglio di un Paese nuovo che si appresta, per la seconda volta nella sua storia, a partire alla conquista di se stesso.

Del resto a riprova dell'ambizione soprattutto monumentale di Brasilia, stanno gli interni di queste fabbriche grandiose i quali molto spesso delludono per la sommarietà e convenzionalità delle soluzioni, quase che lo slancio celebrativo si sai esaurito nelle strutture principali e non si sia curato di abbassarsi alla cura dei particolari. All'originalità seducente delle facciate non corrisponde infatti analoga originalità dietro le facciate: immense sale sfondate e serpeggianti, dai soffitti eccessivamente bassi, disseminate di tozze colonne cilindriche, cosi da far rimpiangere le tradizionali divisioni per mezzo di pareti e di porte; scalinate larghe e prive di balaustrate, che portano dal primo al secondo piano senza alcuna maestà come nei magazzini e nei docks; soprattutto cemento armato dovunque, anche là dove ci si aspetterebbe l'impiego per il rivestimento e la decorazione di materiali più belli e più pregiati.

L'edificio così ardito all'esterno, si rivela, insomma, pigro e frettoloso all'interno. Né si può obiettare che anche qui il giudizio è prematuro perchè l'edificio non è ancora rifinito negli ultimi particolari. Per esempio la sala del Parlamento, che sta tutta racchiusa nell'immensa scodella ritta, è pronta. Ebbene, niente in questa sala corresponde all'ardimento all'esterno. Ė una bella sala comoda, alta, severa, ma nulla di più.

Se gli edifici del Governo mirano ad esprimere il senso dell'accentramento e della potenza dello Stato, il palazzo dell'Alvorada, dimora del Presidente della 
Repubblica, ossia l'equivalente del nostro Quirinale, sembra invece suggerire l'idea di una serenità contemplativa e di un raccoglimento filosofico ed estetico, quasi che la Repubblica del Brasile fosse la repubblica di Platone retta da saggi unicamente con criteri di saggezza. Niente linee verticali, dunque, e niente gigantismo. Un grande porticato corre per tutta la lunga facciata orizzontale, specchiandosi nell'acqua limpida di un vasto bacino dai colori chiari e brillanti di maiolica. In luogo di collone il porticato ha vele di pietra, sagomate in modo che sembrano gonfiarsi ad un vento marino, come viste di scorcio, larghe in basso e in alto e strette nel mezzo, riminiscenti forse della barca nazionale, la jangada di Recife e di Bahia, o forse delle vele delle navi dell'Iliade. Il cielo azzurro dell'altipiano che vaneggia tra l'una e l'altra di queste vele bianche; il sole dei tropici che quassù a Brasilia risplende ma non scotta; il silenzio profondo che emana dalla boscaglia prossima; il grave volo di alcuni avvoltoi neri; tutto qui fa pensare ai luoghi e monumenti dell'antichità mediterranea di cui l'architetto sembra essersi ricordato disegnando questo palazzo. E certamente Oscar Niemayer, con l'Alvorada, ha creato qualche cosa di molto vicino al capolavoro. Se non altro ce lo fa capire l'identità tra l'intenzione dell'architetto e l'effetto che l'edificio produce sul visitatore. Non c'è alcuna retorica nell'Alvorada bensì una fusione felice di elementi ambientali e ideali: così che se non ci fossero le due sentinelle con il mitra sotto il braccio che misurano a passi scanditi le lastre di marmo bianco dello spiazzo, non ci sarebbe difficile, seguendo il gioco delle analogie, trasportarci con l'immaginazione assai lontano dal Brasile, in Persia oppure in Grecia.

Ma l'interno dell'Alvorada non rassomiglia all'esterno, al solito. Si passa dal porticato luminoso e meditativo a delle grandi sale liete e comode che potrebbero esser quelle di un contry-club americano. Nell'atrio le pareti sono ricoperte di uno scintillante rivestimento aureo; tende modernistiche velano le immense vetrate; poltrone e divani stanno disposti nei soliti ordini convenzionali. Insomma alla semplicità della repubblica platonica a cui pareva alludere il porticato subentrano il lusso e il fasto dei regni ellenistici. Lo stesso singolare contrasto del resto si nota tra l'esterno e l'interno della piccola e assai originale cappella che si trova presso il palazzo. Esternamente essa rassomiglia ad una candida conchiglia ravvolta su se stessa come per meglio celare, nel più intimo dei suoi ravvolgimenti, l'altare e i riti: ma internamente, ahimè, invece di lasciarla Bianca come appunto sono le conchiglie, si è preferito di rivestirla di stucco o forse legno dorato, rigato dall'alto in basso, come certi astucci per le sigarette.

Il tramonto ci coglie alla fine della visita frettolosa di Brasilia con una repentinità tradittrice. Un momento prima il sole riempiva con la sua luce vitale gli stradoni asfaltati e deserti, gli sterrati sanguigni, la boscaglia polverosa; un 
momento dopo, ecco che l'ombra della sera sottrae quella vitalità dall'aria che imbrunisce e d'improvviso, mentre corriamo alla volta dell'aeroporto, sorpassati e seguiti da numerosi camión gremiti di operai che rientrano dai cantieri, l'atmosfera intorno a noi si fa straniera e ostile. La boscaglia tropicale che avevamo dimenticato visitando i razionali edifici della città ci riappare, gialla e decrépita, dietro il tatuaggio violetto di qualche indicazione stradale al neon. Le miriadi di lampade bianche che si allontanano nella notte, sembrano sprofondare in un buio senza fine. E tutto ad un tratto si sente la mancanza, tra tanta monumentalità di palazzi statali e tanta levigatezza di asfalti, delle umili case e delle umili strade che altrove testimoniano la presenza di un'umanità forse poco ambiziosa ma fedele e radicata. Così, dopo la visita, Brasilia ci riappare come l'avevamo intuita dall'aeroplano arrivandoci: un atto di coraggio pionieristico; il símbolo di una volontà di conquista; la dimostrazione di una possibilità lungimirante. Alla luce di questa riflessione il gigantismo di Brasilia appare spiegato; come il barocco delle chiese costruite nelle città della costa dai primi colonizzatori.

Corriere della Sera, 28 agosto 1960.

\section{Referências}

DE SOUZA, Vilma De Katinsky Barreto. "Os relatos de viagem de Moravia: o distanciamento histórico e a procura da realidade sem maravilha". Texto apresentado no IV Encontro Nacional. ANPOLL, Grupo de Trabalho Literaturas Estrangeiras. São Paulo, 1989.

ELKANN, Alain. Vida de Moravia. Lisboa: Edição Livros do Brasil, 1992.

MARCOLINI, Adriana. "O Brasil nos relatos de jornalistas italianos: o sguardo de Massimo Bontempelli e Alberto Moravia". Tese de mestrado. São Paulo: Faculdade de Filosofia, Letras e Ciências Humanas, Universidade de São Paulo, 2003.

MORAVIA, Alberto. VIAGGI. Articoli 1930-1990. Milano: Bompiani, 1994. 